\title{
Spectrum of left atrial thrombus in rheumatic heart disease
}

Himanshu Mahla, Kaushal Kumar Harlalka, Shivakumar Bhairappa, Cholenahally Nanjappa Manjunath

Department of Cardiology, Sri Jayadeva Institute of Cardiovascular Sciences \& Research, Bangalore, Karnataka, India

\section{Correspondence to}

Dr Shivakumar Bhairappa, snbhairappa@gmail.com

Accepted 8 April 2014

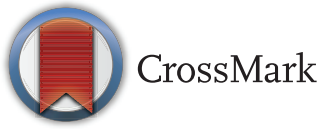

To cite: Mahla $\mathrm{H}$, Harlalka KK, Bhairappa S, et al. BMJ Case Rep Published online: [please include Day Month Year] doi:10.1136/bcr-2014204370

\section{DESCRIPTION}

We describe six patients with rheumatic heart disease involving mitral valve with predominant mitral stenosis. Figures 1-6 and videos 1-6 show the spectrum of left atrial thrombus in rheumatic heart disease. All patients had severe mitral stenosis with functional class III symptoms. All patients had atrial fibrillation. The patient in figure 1 (video 1) had left atrial appendage (LAA) thrombus. This patient underwent successful balloon mitral valvotomy (BMV). The patient in figure 2 (video 2) had LAA thrombus protruding into the left atrial cavity. This patient did well after BMV. The patient in figure 3 (video 3 ) had thrombus in the left atrial roof but above the plane of fossa ovalis with a good result of BMV. Figure 4 (video 4) shows

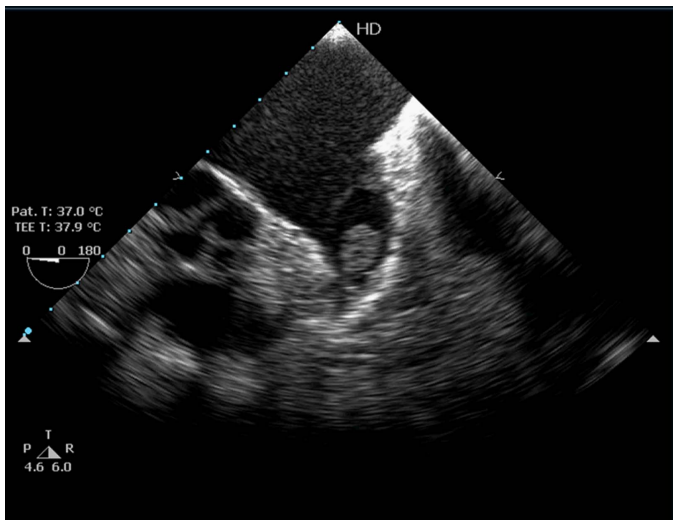

Figure 1 Transoesophageal echocardiogram $180^{\circ}$ view (4 chamber) showing thrombus in the left atrial appendage.

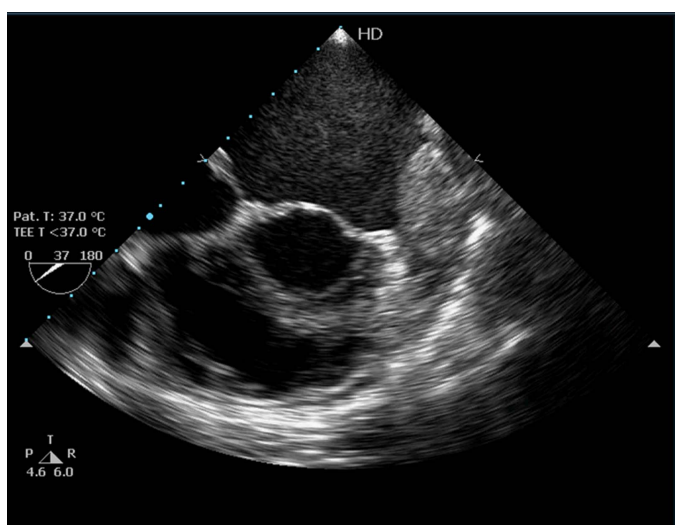

Figure 2 Transoesophageal echocardiogram $40^{\circ}$ view (aortic short axis) showing thrombus in the left atrial appendage protruding into the left atrial cavity.

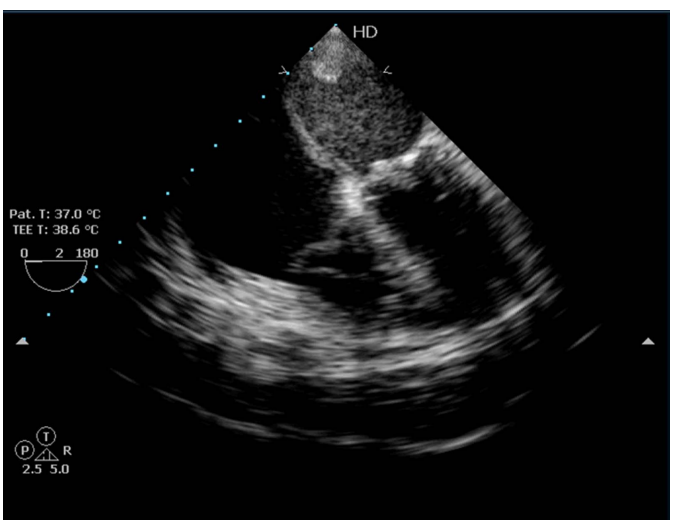

Figure 3 Transoesophageal echocardiogram $0^{\circ}$ view (4 chamber) showing thrombus in the left atrial roof but above the plane of fossa ovalis.

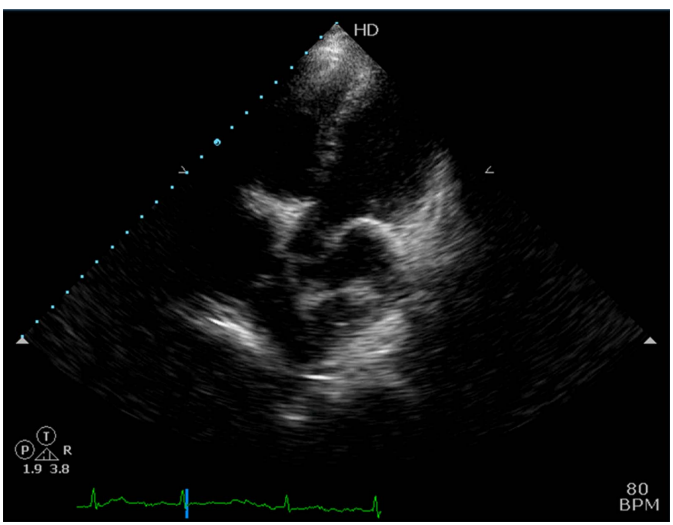

Figure 4 Transthoracic echocardiogram apical four-chamber view showing the thrombus attached to the left atrial roof but extending below the plane of fossa ovalis.

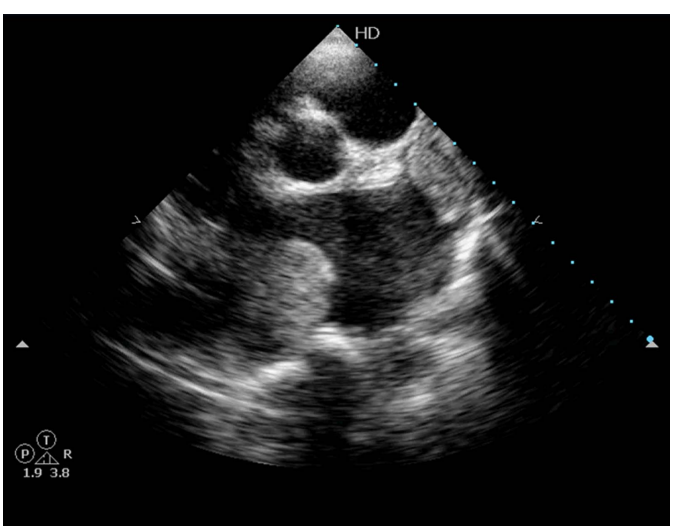

Figure 5 Transthoracic echocardiogram short axis view showing thrombus in the left atrial and in the left atrial appendage. 


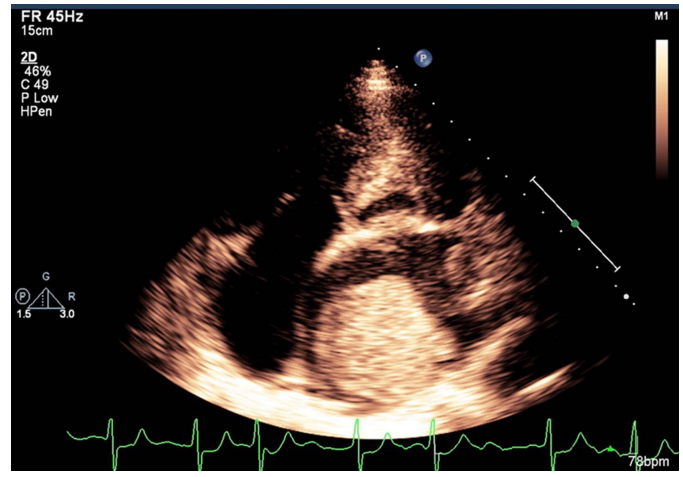

Figure 6 Transthoracic echocardiogram apical four-chamber view showing large thrombus in the left atrial (LA) filling most of the LA.

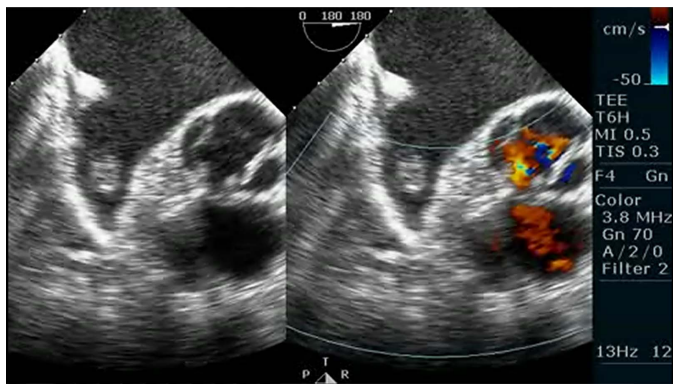

Video 1 Transoesophageal echocardiogram $180^{\circ}$ view (4 chamber) showing thrombus in the left atrial appendage.

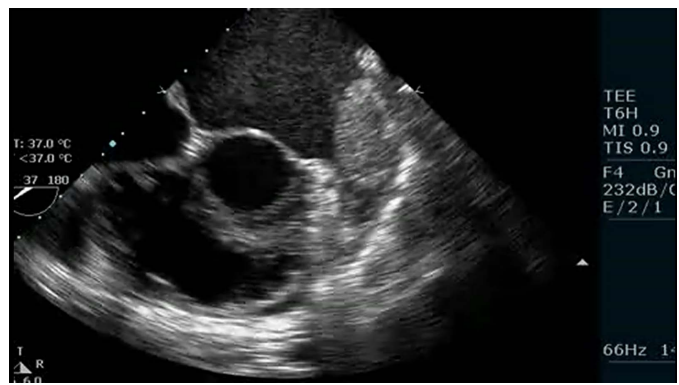

Video 2 Transoesophageal echocardiogram $40^{\circ}$ view (aortic short axis) showing thrombus in the left atrial appendage protruding into the left atrial cavity.

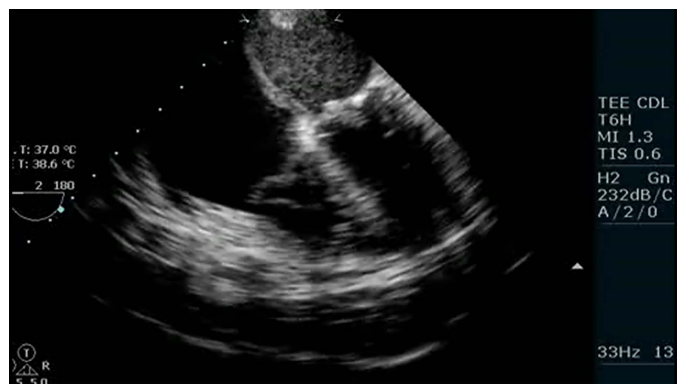

Video 3 Transoesophageal echocardiogram $0^{\circ}$ view (4 chamber) showing thrombus in the left atrial roof but above the plane of fossa ovalis.

thrombus attached to the roof of the left atrium but reaching below the plane of fossa ovalis. In addition this thrombus had an echolucent centre which gives a clue to the duration of the thrombus, that is, new onset. Figure 5 (video 5) shows thrombus

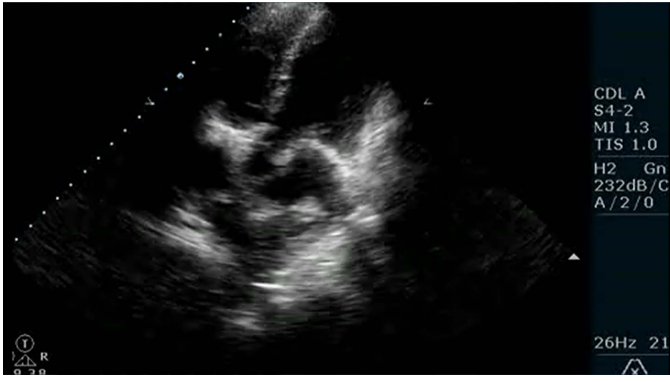

Video 4 Transthoracic echocardiogram apical four-chamber view showing the thrombus attached to the left atrial roof but extending below the plane of fossa ovalis.

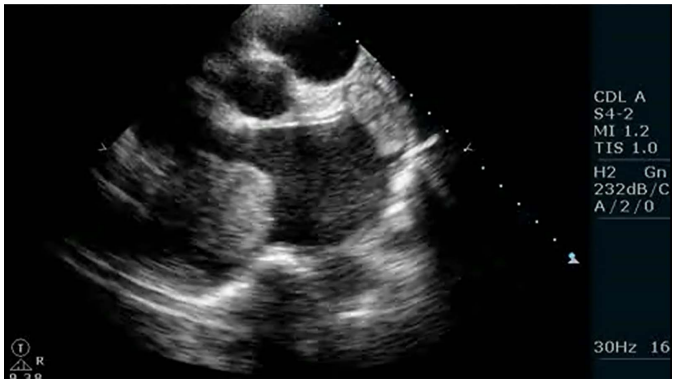

Video 5 Transthoracic echocardiogram short axis view showing thrombus in the left atrial and in the left atrial appendage.

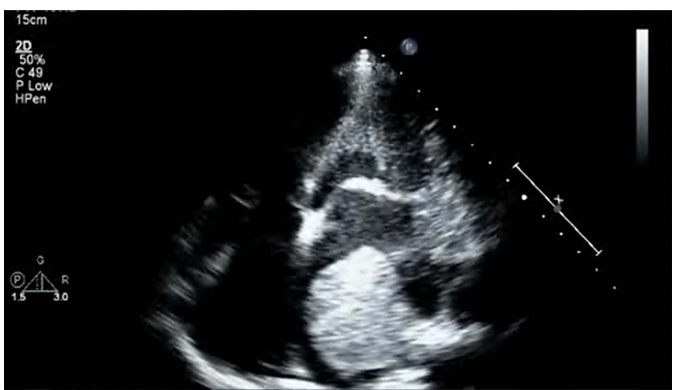

Video 6 Transthoracic echocardiogram apical four-chamber view showing large thrombus in the left atrial (LA) filling most of the LA.

in the left atrium as well as LAA. Figure 6 (video 6) shows thrombus filling almost full of the left atrium. All three patients shown in figures 4-6 underwent surgical management. We can classify $^{1}$ the thrombus in the left atrium as Ia (thrombus confined to LAA), Ib (thrombus in LAA and protruding into LA cavity), IIa (attached to LA roof but above the plane of fossa ovalis), IIb (reaching below plane of fossa ovalis), III (attached to interatrial septum), IV (mobile with attachment to roof or lateral wall) and $\mathrm{V}$ (ball valve thrombus). Types Ia, Ib and IIa can undergo BMV by using modified over the wire technique. ${ }^{2}$ Traditionally, LA thrombus was a contraindication for BMV but it can be carried out in the above scenarios of thrombus with almost $100 \%$ success in the hands of experienced operators. Rheumatic heart disease is a constant burden in developing countries. The most commonly seen lesion is mitral stenosis. Victims are mostly women. Adding to this is the burden of left 
atrial thrombus in the rheumatic mitral stenosis, which significantly alters the management.

\section{Learning points}

- Rheumatic heart disease with mitral stenosis can lead to the formation of thrombus formation. Atrial fibrillation adds to the risk.

- Classifying the thrombus according to the location can be a useful guide to management strategy.

- In selected cases of thrombus in the left atrium or appendage, valvotomy can be carried out safely by over-the-wire technique.
Acknowledgements The authors thanks Dr Neha Godara for her kind support. Contributors $\mathrm{HM}$ and $\mathrm{KH}$ participated in writing the article, SB participated in corrections and CM participated in the finishing touch.

Competing interests None.

Patient consent Obtained.

Provenance and peer review Not commissioned; externally peer reviewed.

\section{REFERENCES}

1 Manjunath CN, Srinivasa KH, Ravindranath $\mathrm{KS}$, et al. Balloon mitral valvotomy in patients with mitral stenosis and left atrial thrombus. Catheter Cardiovasc Interv 2009:74:653-61.

2 Manjunath $\mathrm{CN}$, Srinivasa $\mathrm{KH}$, Patil CB, et al. Balloon mitral valvuloplasty: our experience with a modified technique of crossing the mitral valve in difficult cases. Catheter Cardiovasc Diagn 1998;44:23-6.

Copyright 2014 BMJ Publishing Group. All rights reserved. For permission to reuse any of this content visit http://group.bmj.com/group/rights-licensing/permissions.

BMJ Case Report Fellows may re-use this article for personal use and teaching without any further permission.

Become a Fellow of BMJ Case Reports today and you can:

- Submit as many cases as you like

- Enjoy fast sympathetic peer review and rapid publication of accepted articles

- Access all the published articles

- Re-use any of the published material for personal use and teaching without further permission

For information on Institutional Fellowships contact consortiasales@bmjgroup.com

Visit casereports.bmj.com for more articles like this and to become a Fellow 